\title{
Türk Eğitim Derneği Ankara Koleji Vakfı Kütüphaneleri
}

\author{
Libraries of the Ankara College Foundation of the \\ Turkish Education Society
}

\section{Selda Arıkan"}

\section{Öz}

Bu makalede Türk Eğitim Derneği Ankara Koleji Vakfı kütüphaneleri ve bu kütüphanelerin son yıllarda gerçekleştirdikleri etkinlikıer kısaca tanıtılmaktadır.

Anahtar Sözcükler: Okul kütüphaneleri; TED Ankara Koleji Vakfı Kütüphaneleri

\section{Abstract}

This paper introduces the Libraries of the Ankara College Foundation, a K-12 institution, along with the most recent activities thereof.

Keywords: School libraries; Turkish Education Society Ankara College Foundation Libraries

\section{Giriş}

İnsanın en önemli gereksinimlerinden birinin bilgi olması, bugüne ve geleceğe yönelik bütün yatırımlarda bilgi kaynaklarına ve bilgiye büyük önem verilmesini sağlamıştır. Bu doğrultuda "bilgiyi" ortak konu edinen iki kurum: "kütüphaneler" ve "eğitim- öğretim kurumları olan okullar" bir araya gelmiştir. Eğitimin temel ve vazgeçilmez bilgi kaynaklarından biri olan kitap ve her türlü yayının korunduğu, sergilendiği ve hizmete sunulduğu yerler olan kütüphaneler, büyük bir hızla gelişen eğitim ve iletişim teknolojilerine rağmen günümüzde önemini ve işlevini yitirmemiş, aksine, yeni teknolojilerin sağladığı imkânlarla zenginleşerek eğitimdeki yerini ve işlevini artırmıştır.

\footnotetext{
- Kütüphaneci, TED Ankara Koleji Kütüphane ve Dokümantasyon Merkezi (sarikan@ tedankara.x12.tr).
} 
Kütüphanelerin bilginin birikim, iletim ve kullanım merkezi olması, okullarda ise gerçekleştirilen hizmetlerin bilgiye yönelik özelliği bu iki kurumu eğitimöğretim ortamında birleştiłmiştir. Okul kütüphaneleri adı altında hizmet veren merkezler bilginin en verimli biçimde paylaşıldığı yerler haline gelmiştir. Eğitim ve öğretimin amaçlarına ulaşmasında, kütüphane hizmetlerinin tümünü içeren zengin bir program, okulların öncelikle gözönünde bulundurması gereken koşul olarak ortaya çıkmıştır.

Okul kütüphaneleri; eğitim ve öğretim için gerekli her türlü bilgi kaynağını toplayan, düzenleyen, hizmetleri ile parçası bulunduğu öğretim kademesinin amaçlarının gerçekleşmesine dinamik bir şekilde katılan ve çağın gereksinimlerine uygun olarak gelişen toplumşal kurumlardır. Hizmet vermekle yükümlü oldukları okuldaki öğretmenlerin, öğrencilerin, yöneticilerin, personelin ve gerektiğinde bulunduğu toplumun bilgi gereksinimlerini karşılamak zorundadır.

Türk Eğitim Derneği (TED) Ankara Koleji Vakfı okulları çağın koşullarına ve gelecek beklentilerine uygun olarak eğițm-öğretim çalışmalarını sürdürmektedir. Kurumumuzda eğitim kalitesinin yükseltilmesine, yaşam boyu eğitimin gerçekleştirilmesine ve bilgi gereksinmelerinin karşılanmasına büyük önem verilmektedir. Günümüzün öğrencileri yarının bilgi üreticileri ve kullanıcılarıdır. Hayatlarının en önemli devresinde edinecekleri deneyimler yarınlarını olumlu biçimnde etkileyecektir.

TED Ankara Koleji Vakfı liköğretim 1. ve 2. Kademe ve Lise Kütüphanesi modern okul kütüphaneciliğine uygun standartlarda hizmet vermek üzere yeniden organize edilmiştir. Bu kütüphanelere ilave olarak öğretmenler için Araştırma Kütüphanesi kurulmuştur.

\section{TED Ankara Koleji Vakłı Kütüphane ve Dokümantasyon Merkezi}

TED Ankara Koleji Vakłı İlköğretim 1. ve 2. Kademe ile Lise ve Araştırma Kütüphanelerinin amacl; okulun eğitim ve öğretim programlarına etkin bir şekil- 
de katkıda bulunmak; öğretmenlerin mesleki çalışmalarına yardımcı olmak; öğrencilerin derslerini olduğu kadar boş zamanlarını da en iyi şekilde değerlendirmelerini ve yapıcı, eleştirici ve estetik değerlere ilgi duymalarını sağlamak; bütün kullanıcıların düşünme yeteneğinin geliştirilmesi ve bilgi gereksinimlerinin karşılanması için her türlü bilgi kaynağını sağlamak, düzenlemek ve hizmete sunmaktır.

\section{Örgüt Yapısı}

Kütüphanelerin koordinasyonu, yönetimi ve hizmetleri aşağıdaki şekilde yürütülmektedir:

1. Kütüphane ve Dokümantasyon Merkezi Müdürü;

2. Ilköğretim 1. ve 2. Kademe Kütüphaneleri ile Lise Kütüphanesi Şefleri, Araştırma Kütüphanesi Şefi.

Kütüphane ve Dokümantasyon Merkezi Müdürü TED Ankara Koleji Vakfı Genel Müdürlüğüne, Kütüphane Şefleri ise Merkez Müdürlüğüne bağlı olarak çalışmalarını yürütmektedir.

\section{Personel}

Dinamik ve başarılı bir hizmetin verilmesinde personelin, özellikle mesleki eğitim görmüş kütüphanecilerin önemi bilinmektedir. Błr okul kütüphanecisinin yönetimsel sorumlulukları olduğu kadar eğitimsel ve toplumsal sorumlulukları da vardır. Kurumumuz bu özellikleri esas alarak, kütüphanecilik eğiti* mi görmüş, eğitim ve öğretim teknikleri konusunda bilgili, bilgi kaynaklarının seçimi, düzenlenmesi, kullanılması, kütüphane otomasyonu ve enformasyon teknolojileri konusunda uzman sekiz kütüphaneciyi kadrosuna dahil etmiştir. Şu anda bir müdür ve sekiz kütüphaneci vardır. Personelin dağılımı aşağıdaki gibidir: 
Kütüphane ve Dokümantasyon Merkezi Müdürü: Kütüphaneci

İ|köğretim 1. Kademe Kütüphanesi : 1 Şef Kütüphaneci, 1 Kütüphaneci

İlköğretim 2. Kademe Kütüphanesi : 1 Şef Kütüphaneci, 1 Kütüphaneci

Lise Kütüphanesi

Araştırma Kütüphanesi

: 1 Şef Kütüphaneci, 1 Kütüphaneci

: 1 Şef Kütüphaneci

Bilgi Kaynaklan ve Koleksiyon

Kütüphanęlerin koleksiyonları, yukarıdaki amaçların gerçekleştirilmesi doğrultusunda; kitaplar, süreli yayınlar, danışma kaynakları, görsel-işitsel materyaller (CD-ROM, video, kaset, poster vb.) ve elektronik bilgi kaynaklarından meydana gelmektedir. Kütüphanelerimizde bulunan kaynaklar Dewey Onlu Sınıflama sistemine göre sınıflandırılarak, kullanıcıların kendi başlarına araştırma yapmalarına imkân tanıyan açık raf sistemine göre raflara yerleştirilmiştir. 1997-1998 öğretim yılında kütüphanelerde bulunan materyal sayısı toplam 9.000 iken şu anda bu sayı 23.000 civarındadır.

\section{Kütüphane Otomasyonu}

Kütüphanelerde yapılmakta olan sağlama, kataloglama, ödünç verme, süreli yayınların denetimi ve danışma hizmetlerini bilgisayara dayalı olarak gerçekleştirmek, kütüphane yönetiminde bilgisayar ve uzakiletişim teknolojisi başta olmak üzere enformasyon teknolojisinin tüm ürünlerinden yararlanmak "Kütüphane Otomasyonu" olarak tanımlanabilir.

TED Ankara Koleji Vakfı Kütüphane ve Dokümantasyon Merkezi 1 Temmuz 1998 tarihinde otomasyon çalışmalarına başlamıştır. Bu amaç doğrultusunda yazılım seçimi yapılmış ve Bilkent Üniversitesi tarafından geliştirilen BLISS-PC yazılımı satın alınmıştır. Bir yıl gibi kısa bir süre içinde kütüphanelerde bulunan bütün materyallerin bibliyografik bilgileri bilgisayar ortamına aktarılmış ve yukarıda adı geçen hizmetler (kataloglama, çevrimiçi katalog taraması, sipariş, ödünç verme vb.) bilgısayar üzerinden verilmeye başlanmıştır. BLISS-PC'nin web modülü olmayışı nedeniyle Kasım 1999'da BLISS-Li- 
nux satın alınmış, eski sistem üzerinde bulunan bütün veri tabanları bu sisteme aktarılarak Aralık 1999'da kütüphanelerimizde bulunan bütün materyallerin bibliyografik künyeleri Internet üzerinden taramaya açılmıştır. Böylece kullanıcılarımız kütüphane kataloğuna her yerden erişme olanağına kavuşmuşlardır. Aynı tarihte kütüphane web sayfası (http://library.tedankara.k12.tr) hazırlanarak kullanıcılarımızın hizmetine sunulmuştur. Böylece kütüphanemiz basılı ortamdaki materyaller ile birlikte elektronik ortamda bulunan bilgi kaynaklarını da kullanıcıların hizmetine sunmaya başlamıştır.

\section{Kütüphane Hizmetleri}

Kütüphane hizmetleri, kütüphaneye her türlü materyalin ve araç gerecin sağlanmasından kullanıcıya sunulacak duruma getirilmesine kadar yapıması gereken işleri kapsayan "Teknik Hizmetler" ve kullanıma hazır hale gelen kütüphane materyalinin veya bilginin kullanıcıya sunulması işłemini kapsayan "Okuyucu Hizmetleri" olarak iki ana grupta yürütülür.

\section{Teknik Hizmetler}

Seçim ve Sağlama

Güncelliğini kaybetmiş kitaplarla dolu, arşiv niteliği taşıyan, müfredat programlarının gerisinde kalmış bir kütüphane öğretmen ve öğrenciler iç̧in çekici ve cazip olamayacağından, bu tür yayınlar kütüphanelerin koleksiyonundan ayıklanmıştır. Yerlerine güncel olan, kalitesi ve düzeyi eğitimin verildiği yaş grubuna hitap eden, müfredata uygun, boş zamanları değerlendirmek için okumaya elverişli yeni yayıniar alınmıştır. Öğretmenler için yeni kurulan Araştırma Kütüphanesi koleksiyonu da öğretmenlerden gelen talepler ile zenginleştirilmiştir. TED Ankara Koleji Kütüphanelerinin koleksiyonunun yeniden oluşturulmasında ve geliştirilmesinde temel hareket noktası öğretmenlerin ve öğrencilerin gereksinimleridir. Gereksinim terimi ile hem bireysel hem de eğitimsel eğilimlerden ötürü doğan istekler amaçlanmaktadır. 
Bilgi kaynaklarının sağlanmasında satın alma ve bağış söz konusudur. Kaynakların bir kısmı yurt içi, bir kısmı da yurt dışından temin edilmektedir.

\section{Kataloglama ve Siniflama}

1998 yılında başlayan yeniden yapılandırma çalışmaları sırasında kütüphane koleksiyonu gözden geçirilmiş ve güncelliğini kaybetmiş yaklaşık 4000 materyal koleksiyondan çıkarılmıştır. Geriye dönük olarak 1. ve 2. kademe kütüphanelerinde sağlıkঝ bir kataloglama yapılmadığından bütün kataloglama işlemleri yeniden yapıımıştır. Otomasyona geçiş aşamasında kütüphanelerde bułunan bütün materyaller "Dewey Onlu Sınıflama" sistemine göre sınıflanarak "Anglo Amerikan Kataloglama Kuralları II"ye göre kataloglanmıştır. İngilizce olan konu başlıkları listeleri Türkçeye çevrilmiş ve materyallere hem Türkçe hem de İngilizce konu başlıkları verilmiştir.

\section{Süreli Yayınlar}

1998 yılından önce kütüphanelerimizin abone olduğu süreli yayın kaydı yoktur. Yeniden yapılandırma çalışmaları ile birlikte, eğitim ve öğretimi destekleyecek bir süreli yayın koleksiyonu oluşturulmaya başlanmış ve 1999 yılı için 14 adedi yurt içi, 99 adedi yurt dışından olmak üzere toplam 113 adet süreli yayına abone olunmuştur. 1999 yılında bu dergilerin içinden çeşitli nedenlerle yayınları duran dergilerin abonelikleri iptal edilmiş ve yeni eklenenlerle birlikte 2000 yılı için 37 adedi Türkçe, 89 adedi yabancı dilde olmak üzere toplam 126 adet dergiye abone olunmuştur.

Ayrıca kütüphanelerde bulunan süreli yayınların elektronik ortamda bulunanlarına da kütüphane web sayfasından ulaşılabilmektedir.

\section{Okuyucu Hizmetleri}

Kütüphanelerimizde öğretmenlerin ve öğrencilerin kütüphane hizmetlerinden yararlanmalarına imkân sağlayacak her türlü girişim ve hizmetler bu grup içinde ele alınıp değerlendirilmektedir. 
Ödünç Verme Hizmeti

Kütüphanelerimizde "Kütüphaneler Yönetmeliği" içinde yer alan ödünç verme kurallarına göre öğretmen ve öğrencilerin tüm bilgi kaynaklarından gerek okul içi, gerekse okul dışında kolaylıkla yararlanabilmelerini sağlayıcı, kısıtlayıcı değil destekleyici nitelikte hizmet verilmektedir. Ödünç verme işlemleri BLISS-Linux Kütüphane Otomasyon Sisteminin Dolaşım Modülü ve barkod etiket ve okuyucuları kullanılarak yapılmaktadır.

\section{Danısma Hizmeti}

Kütüphanelerde kullanıcılara yardımı hedef alan bir hizmettir. Temelde kullanıcı ile bilgi kaynakları arasında bağ kurma fikrine dayanan bu hizmet, kütüphanelerimizde genellikle çeşitli olayların ve soruların araştırıması, aranan bir bilgi kaynağının veya bilginin bulunması ve belirli bir konuda bibliyografya hazırlanması gibi işlemleri kapsamaktadır.

- Internet ve Veri Tabanlarnnn Kullanım: Gelişmekte olan bilgi teknolojileri, pek çok okulda Internet veri tabanları ile eğitimin desteklenmesini gündeme getirmiştir. Eğitimde araştırıcılığı, görsel zenginliği ve yorumlama yeteneğini geliştirici bu tür destek materyallerinden okulumuz öğretmen ve öğrencilerinin, ilgili birimlerin yararlanmasını sağlamak amacı ile, Kütüphane ve Dokümantasyon Merkezinde, elektronik veri tabanları 11 Eylül 1998 tarihinden itjbaren kullanılmaya başlanmıştır. Ilık bağlantı deneme amaçı olarak EBSCOhost Reference Center ile yapılmıştır. Iki aylık bu deneme bağlantısında 1283 adet tarama yapılmış ve bunun sonucunda 1331 sayta tam metin makale okunmuştur. Bununta birlikte CD-ROM üzerinde bulunan ERIC ve MLA veri tabanları 1999 tarihinden itibaren kullanımaya başlanmış ve bu iki veri tabanından 35 öğretmen ve 265 öğrenci yararlanmıştır. 1999-2000 döneminde ERIC ve MLA adlı veri tabanlarının kullanımı izlenmiş ve kullanıımadıkları için abonelikleri iptal edilmiştir. Bunların yerine elektronik ortamda bulunan, EBSCO tarafından sunulan, okullar için hazırlanmış elektronik veri tabanları paketine abone olunmuştur. 1 Eylül 1999 - 30 Haziran 2000 tarihleri arasinda bu veri tabanlarindan toplam 2190 tarama yapılmıs, bunun sonucunda 23.695 sayfa (4526 makale) elektronik ortamda kullanicitar tarafindan alınmıştır. Ayrıca çeşitli zamanlarda 1 ay süreli olarak 16 ayrı veri tabanı deneme amaçlı olarak kullanıcılara sunulmuştur. 
- Web Sayfası Kullanımi: Kasım 1999'da kütüphane web sayfası hazırlanarak kullanıma sunulmuştur (http://library.tedankara.k12.tr). Kasım 199930 Eylül 2000 tarihleri arasında kütüphane web saylası 8500 kişi tarafından ziyaret edilmiştir. 2000 yılı yaz döneminde yapılan çalışmalar sonucunda eğitim ve öğretimi destekleyen ve ödev konuları ile ilgili Türkçe ve yabancı web saytalarının adreslerí toplanmış ve bunlar Dewey Onlu Sınıtlama Sistemine göre hazırlanmış ve kütüphane web sayfasından sunulmaya başlanmıştır. Kütüphane web sayłamız içerik açısından her geçen gün zenginleşmeye devam etmekte ve elektronik ortamda bulunan bilgilere ulaşmak için vazgeçilmez bir site olmayı hedeflemektedir. Ayrıca kütüphaneyle ilgili her türlü bilgiye ulaşılabilecek, materyaller hakkında bilgi alınabilecek ve bilgi istek formu ile istenilen bilgilerin sağlanabileceği önemli bir web saylasıdır. Kütüphane Web saytası ilgili kütüphaneci personel tarafından sürekli olarak yenilenmektedir.

- Kütüphanelerarası Ödünç Verme ve Makale Istekleri: Her biłgi kaynağının her kütüphanede bulunamayacağı düşüncesinden hareketle kütüphanemiz ülkemizde bulunan diğer kütüphanelerden okuyucu istekleri doğrultusunda materyal getirtmektedir. Bu amaçla kütüphanelerarası ödünç verme protokolü ile 26 kitap 2000 yılı döneminde farklı kütüphanelerden getirtilerek isteyen kullanıcıların hizmetine sunulmuştur. Ayrıca kullanıcıların istekleri doğrultusunda 21 (525 sayfa) adet makale yurt dişından elektronik olarak getirtilerek, basıl', formatta kullaniciların hizmetine sunulmuştur. Web sayfası üzerinde bulunan "Bilgi İstek Formu" ile gelen 55 adet tarama isteği kütüphaneye iletilmiş ve bunlar da elektronik veri tabanlarından taramaları yapılarak isteyen kullanıcılara iletilmiştir.

- Güncel Duyuru Hizmeti: Bu hizmet Haziran 2000 yılında başlatılmış ve kütüphanelerin abone olduğu 126 derginin içindekiler sayfaları fotokopi çekilerek aylık olarak bölümlere dağıtılmaya başlanmıştır. Bu amaçla 650 sayta fotokopi çekilmiştir. Ayrıca kütüphanelere yeni gelen materyallerin listeleri hem basılı ortamda hem de kütüphane web sayfasında aylık olarak kuilanıcılara duyrulmaktadır.

- Fotokopi Hizmeti: Aralık 1998'den itibaren kütüphanelerde fotokopi hizmeti de ücretsiz olarak verilmeye başlanmıştır. Bu hizmetle birlikte kullanıcılar ihtiyaç duydukları bilgi kaynaklarının fotokopilerini kütüphane içinde çekmeye başlamışlardır. 
Tablo 1. Yıllara Göre TED Ankara Koleji Vakfı Kütüphaneleri Tarafından Verilen Hizmetler

\begin{tabular}{|l|l|l|l|l|l|}
\hline Hizmetler & $\begin{array}{l}1995- \\
1996\end{array}$ & $\begin{array}{l}1996- \\
1997\end{array}$ & $\begin{array}{l}1997- \\
1998\end{array}$ & $\begin{array}{l}1998- \\
1999\end{array}$ & $\begin{array}{c}1999- \\
2000\end{array}$ \\
\hline Materyal Sağlama & + & + & + & + & + \\
\hline Kataloglama ve sınıflama & + & + & + & + & + \\
\hline Süreli yayınlar & & & & + & \\
\hline Ödünç verme & + & + & + & + & + \\
\hline CD-ROM ve Internet Kullanımı & & & + & + & + \\
\hline Elektronik veri tabanları & & & & + & + \\
\hline Web sayfası kullanımı & & & & & + \\
\hline Kütüphanelerarası ödünç verme & & & & & + \\
\hline Elektronik makale istekleri & & & & & + \\
\hline Güncel duyuru hizmeti & & & & + & + \\
\hline Fotokopi hizmeti & & & & + & + \\
\hline $\begin{array}{l}\text { Oyuncak kullanımı } \\
\text { (ilköğretim 1. Kademe kütüphanesi) }\end{array}$ & & & & + & + \\
\hline Seminer ve toplantılara katılma & & & & + & + \\
\hline Kütüphane oryantasyonu & & & & + & + \\
\hline Kültürel ve sanatsal etkinlikler & & & + & + & + \\
\hline Yönlendirme ve referans hizmeti & & & & & + \\
\hline
\end{tabular}

\section{Bina ve Araçlar}

Kütüphanelerin cazip, renkli ve davetkâr birer mekân olmaları için rafların bir kısmı değiştirilip yenilenmiş, ilave mobilyalar yaptırılmış, poster ve resimler ile kütüphane materyallerine yönlendirme yapan işaretler konulmuştur. İlköğretim 1. Kademe öğrencilerinin el becerileri ve zekâ gelişimlerine yönelik, itgilerini çekecek oyuncaklar alınmıştır.

Kütüphaneler üç ayrı binada hizmet vermektedir. İlköğretim 1. Kademe Kütüphanesi okuma salonundan aynı anda 80, İlköğretim 2. Kademe Kütüphanesinden 50 , Lise Kütüphanesinden de 54 öğrenci oturarak yararlanabilmektedir. Araştırma Kütüphanesi ise Lise Kütüphanesinin içinde bir bölümde hizmet vermektedir. 
Illköğretim 1. ve 2. Kademe ile Lise Kütüphanesinde öğretmen ve öğrencilerin Internet ve CD-ROM veri tabanlarını kullanabilecekleri toplam 14 adet bilgisayar bulunmaktadır. Ayrıca her kütüphanede kütüphane kataloğunun taranabileceği tarama terminalleri mevcuttur.

\section{Bütçe}

TED Ankara Koleji Vakfı Kütüphane ve Dokümantasyon Merkezi kütüphanelerin yurt içi ve yurt dışından bilgi kaynakları sağlamak, süreli yayınlara abone olmak ve kütüphane hizmetleri vermek ve geliştirmek için yılda 50.000 dolar ayrılmaktadır. Bu rakam yıllara ve kütüphane ihtiyaçlarına göre değişmektedir.

\section{Kullanıcı Eğitimi}

Kütüphanenin nasıl kullanılacağını öğrenmek ya da kütüphane olanaklarından üst düzeyde yararlanabilmek için öğrencilere düzenli olarak kütüphane oryantasyon programı düzenlenmektedir. Hizmetiçi eğitim seminerlerinde kütüphaneler ile ilgili sunumlar yapılmaktadır.

Geçen yıl başlayan "Bilgi Okur Yazarlığı Becerileri" (BOB) projesi de halen devam etmektedir. 1999-2000 öğretim yılında, 6. sınıflardan bir sınıf seçilmiş, haftada bir saatten oluşan bir program uygulanmıştır. Çok başarılı olan bu proje, 2000-2001 öğretim yıında tüm 6. sınıflara yayılmıştır. Kütüphaneciler tarafłndan verilen dersler, öğretmen, kütüphaneci ve eğitimci işbirliğinin de güzel bir örneğidir.

\section{Sonuç}

Bilgi hizmetlerinde verimiliğin artırılması ve kutlanıcı gereksinimlerinin daha kolay ve hızlı sağlanabilmesi doğrultusunda TED Ankara Koleji Vakfı kütüphaneleri, fiziksel bir mekânla sınırlı olmayan "elektronik kütüphaneler" durumuna gelerek, kullanıcılarının bilgiye olan gereksinimlerini karşılamada vazgeçilmez bir unsur olmayı amaçlamaktadır. Bu amacına ulaşmak için her geçen gün hizmetlerine bir yenisini ilave etmeye ve okul kütüphaneleri ve kütüphaneciliği konusunda öncülük yapmaya devam edecektir. 